\title{
Glass Stiffness Contribution of Flat and Curved Cable-net Supported Glass Façade Systems
}

\author{
Mustafasanie M. Yussof ${ }^{1, *}$, Gerard Parke ${ }^{2}$, Mohd Khairul Kamarudin ${ }^{3}$ \\ ${ }^{1}$ School of Civil Engineering, Universiti Sains Malaysia, Nibong Tebal, Penang, Malaysia. \\ ${ }^{2}$ Department of Civil and Environmental Engineering, Faculty of Engineering and Physical Sciences, University of \\ Surrey, United Kingdom \\ ${ }^{3}$ Faculty of Civil Engineering, Universiti Teknologi MARA, Shah Alam, Selangor, Malaysia.
}

*Corresponding author: cemustafa@usm.my

\begin{abstract}
Glass used in building facade presents an aesthetic feature as well as contributes to the structural stiffness of the whole structural system of the building. In this research, the contribution of glass on the stiffness of the cable-net supported glass facade systems was investigated via experiments. Two generic configurations of cable-net system were considered, namely flat and curved cable-net system, both with and without glass panes. Each system was subjected to static load. The results indicated that the introduction of certain level of curvature to the cable net structure has increased the stiffness of the cable net structure by $11.5 \%$. The glass panes made significant contributions to the stiffness of the whole structural system. The glass stiffness contribution for flat cable-net system was high at the early stage of loading (approximately $40 \%$ ) but reduced when the load was increased. However, the glass stiffness contribution for curved cable-net increased gradually as the load was increased. For both configurations, the glass stiffness contribution remained steady at about $18 \%$ of the whole structural stiffness as the cables in the cable-net stiffened up to the maximum load.. Based on the static tests carried out, the pre-stress force in the cables in the cable-net systems can possibly be reduced should the glass be considered in the analysis design of cable-net structure. Moreover, the curved cable-net could be designed to have lower pre-stress force in cables compared to that of flat cable-net to meet the deflection criterion of the cable-net structure.
\end{abstract}

Keywords_ Flat cable net, Curved cable net, Glass stiffness contribution, Structural glass façade, Glass, Cable structure

\section{INTRODUCTION}

$\mathrm{C}$ able net structures are widely used as supporting structure for glass façades. The lightweight cable structure is flexible with large deflection under loading. It is usually designed by considering the intensity of wind loading on the glass façade which is transferred to the cable net structure via the glass support attachment. The force in the cables as well as the size of the cables must be designed accordingly to fulfill the deflection criterion of the cable net. This is usually taken as $1 / 40$ to $1 / 50$ of the shortest length of cable in cable net structure. The design force in the cables is one of the main parameters that influence the stiffness of the cable net structure [1,2]. Larger forces in the individual cables may result in the need for a stiff supporting structure in which to anchor the cables.

The rigidity of the supporting structure can be optimized by reducing the amount of force in the cable without jeopardizing the design requirement of the cable net structure. Typically, the shape of a cable net structure such as a doubly-curved net with or anticlastic curvature improves the stability of the structure. The contribution of glass is usually not taken into consideration in the design of cable net structure supported glass façade systems. This approximation is usually made in order to simplify the design process. However, the glass panes supported by cable net structure have significant contribution in increasing the stiffness of the cable net structure $[3,4,5]$. By neglecting the glass, the optimum design of cable net structures cannot be achieved. There are also other factors that need to be considered to achieve optimum design. But only the influence of the cable net configuration and the glass on the stiffness of cable net structure was considered in this study. This paper reports the behavior of cable net structure of different configurations under static loading. In addition, the influence of glass on the stiffness of the cable net structure is also discussed.

\section{METHOD}

\section{A. Experimental Model of Cable-net with and without the Attachment of Glass Panel}

In general, Figure 1 shows the setup of the experimental model of a 7 by 7 cable net structure that was supported by a rigid steel frame at the University of Surrey, UK. There were two configurations of cable nets considered in this study namely a flat cable net and a doubly-curved cable net. Four experimental models were considered in this study; these were flat cable net without glass panes (FCN), flat cable net with glass panes (FCNG), curved cable net without glass panes $(\mathrm{CCN})$ and curved cable 


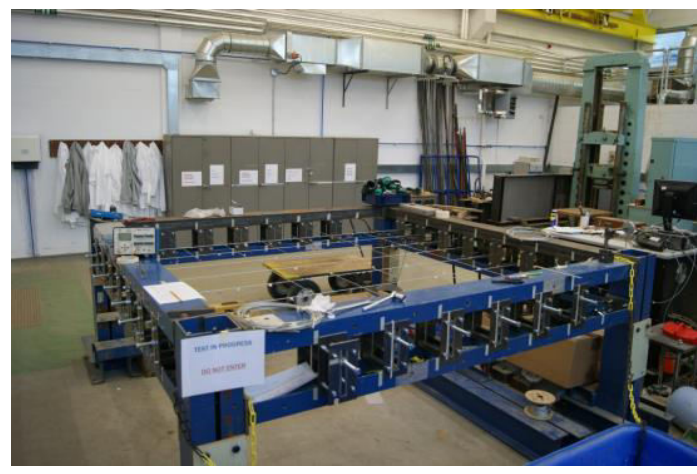

Figure 1. The experimental model of cable net supported glass façade systems
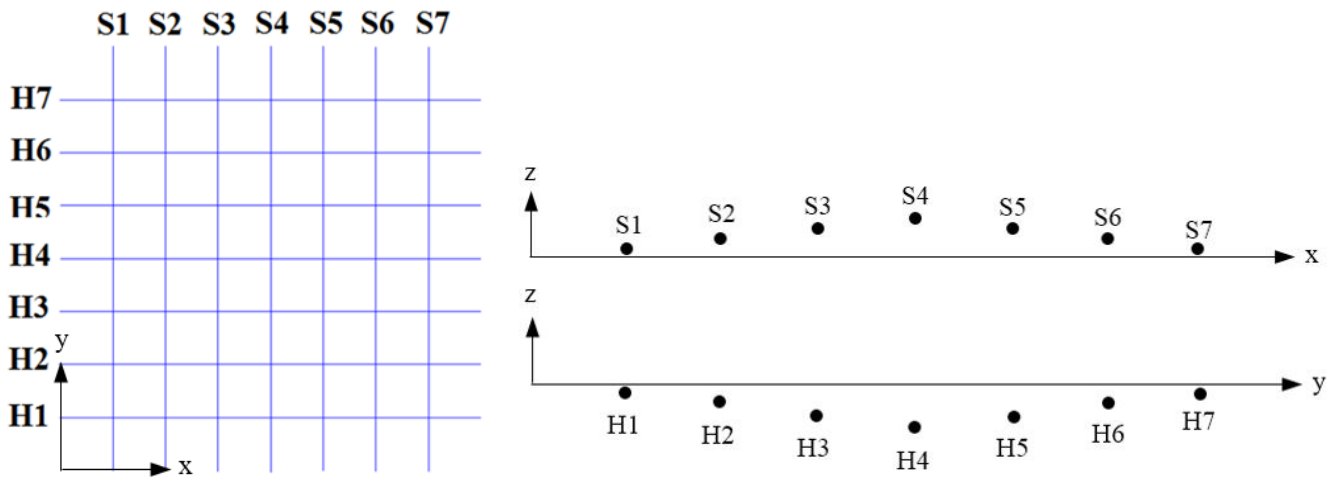

Figure 2. The position of supporting (H1-H7) and load bearing (S1-S7) cables of cable net systems

Table 1. The position of the cable ends measured from the origin point of the axes for the two cable net structures.

\begin{tabular}{|c|c|c|c|c|c|c|c|c|c|c|c|c|c|c|c|c|}
\hline \multirow{3}{*}{$\begin{array}{c}\text { Cable } \\
\text { net } \\
\text { shape }\end{array}$} & \multicolumn{8}{|c|}{ Supporting cables } & \multicolumn{8}{|c|}{ Load bearing cables } \\
\hline & \multicolumn{2}{|c|}{$\mathrm{H} 4$} & \multicolumn{2}{|c|}{ H3 \& H5 } & \multicolumn{2}{|c|}{ H2 \& H6 } & \multicolumn{2}{|c|}{ H1 \& H7 } & \multicolumn{2}{|c|}{ S4 } & \multicolumn{2}{|c|}{ S3 \& S5 } & \multicolumn{2}{|c|}{ S2 \& S6 } & \multicolumn{2}{|c|}{ S1 \& S7 } \\
\hline & $\mathrm{y}$ & $\mathrm{z}$ & $\mathrm{y}$ & $\mathrm{Z}$ & $\mathrm{y}$ & $\mathrm{Z}$ & $\mathrm{y}$ & $\mathrm{z}$ & $\mathrm{x}$ & $\mathrm{z}$ & $\mathrm{x}$ & $\mathrm{z}$ & $\mathrm{x}$ & $\mathrm{Z}$ & $\mathrm{x}$ & $\mathrm{z}$ \\
\hline FCN & 0 & 0 & 305 & 0 & 915 & 0 & 1220 & 0 & 0 & -7 & 305 & -7 & 915 & -7 & 1220 & -7 \\
\hline $\mathrm{CCN}$ & 0 & -30 & 305 & -23 & 915 & -16 & 1220 & -9 & 0 & 31 & 305 & 16 & 915 & 9 & 1220 & 2 \\
\hline
\end{tabular}

net with glass panes (CCNG). The cables were $4 \mathrm{~mm}$ in diameter, rope core with an average modulus of elasticity of $83 \mathrm{kN} / \mathrm{mm}^{2}$. The end fitting of the centre cable of curved cable net was positioned at $30 \mathrm{~mm}$ from the position of the centre cable of flat net. The position of end fitting for the other cables is given in Table 1 and as illustrated in Figure 2. For models $\mathrm{CCN}$ and $\mathrm{CCNG}$, cables H1-H7 and cables S1-S7 were initially in hogging and sagging shapes respectively. All cables were prestressed to approximately $2000 \mathrm{~N}$ which is $20 \%$ of the minimum breaking load of the cables used $(10200 \mathrm{~N})$. The accuracy of the initial pre-stress force in the cables was measured at $\pm 20 \mathrm{~N}$. The cables that span in both inplane directions were held together at their intersection by a $25 \mathrm{~mm}$ by $25 \mathrm{~mm}$ square block as shown in Figure 3 . The experimental model of the cable nets with the glass panes was setup similarly to the ones without the glass panes. The glass was clamped to the cables using a pair of $75 \mathrm{~mm}$ by $75 \mathrm{~mm}$ thin square steel plates. The plates were attached onto the square block as shown in Figure 4. Toughened glass was used in this study with the size of individual glass panes being $300 \mathrm{~mm}$ by $300 \mathrm{~mm}$ by 4 $\mathrm{mm}$ thickness. The pre-stress force in each cable should certainly to have approximately $2000 \mathrm{~N}$ once the glass was fixed to the cable net.

\section{B. Cable-nets Subjected to Static Loading}

All experimental models were subjected to the static load under displacement control that was applied at four nodes of the cable net. The respective nodes were shown in Figure 5. The load was applied by simultaneously pulling down the four nodes of the cable net via a loading frame and was increased to a maximum of approximately $200 \mathrm{~N}$ for each node. Prior to this loading scheme, the loading frame was first hung at the four nodes. Weight of the loading frame which is $3 \mathrm{~kg}$ was considered to be initial loading and was assumed to be evenly distributed to all four nodes. Thus, the total load for each node was approximately $208 \mathrm{~N}$.

\section{Glass Stiffness Contribution (GSC)}




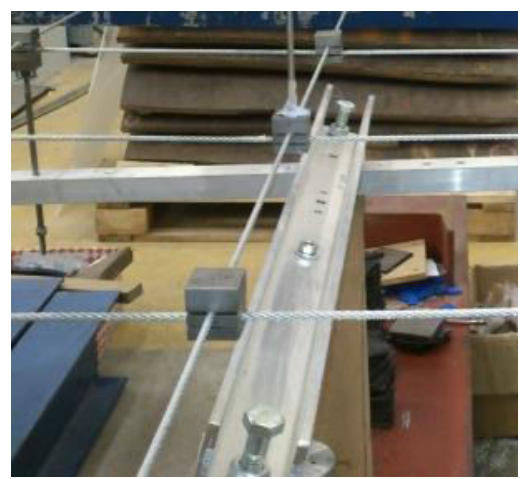

Figure 3. A square block of $25 \mathrm{~mm}$ by $25 \mathrm{~mm}$ use to clamp cables S1-S7 and H1-H7 together.

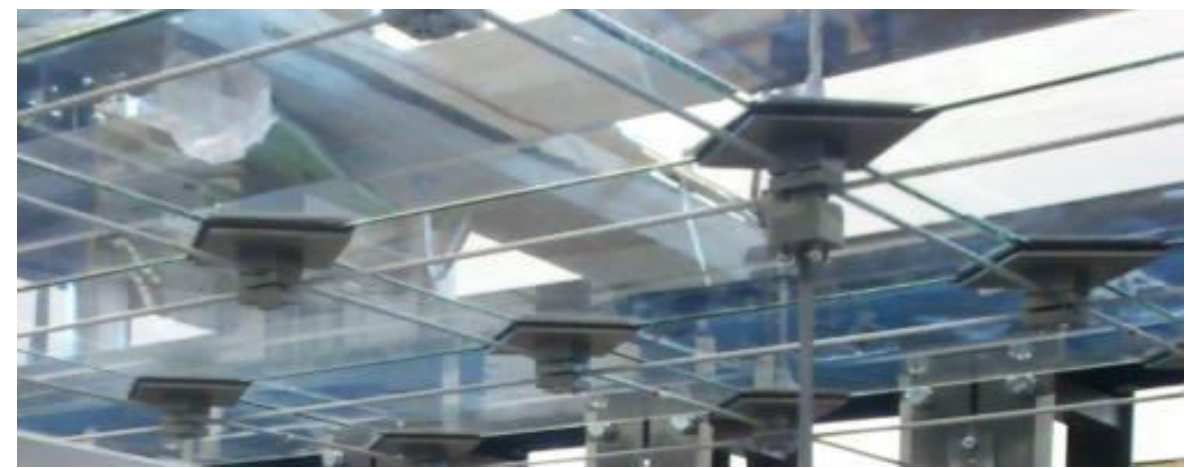

Figure 4. A pair of $75 \mathrm{~mm}$ by $75 \mathrm{~mm}$ of square plates used to clamp the glass to the cable network which fited on top of the cable to cable clamp block.

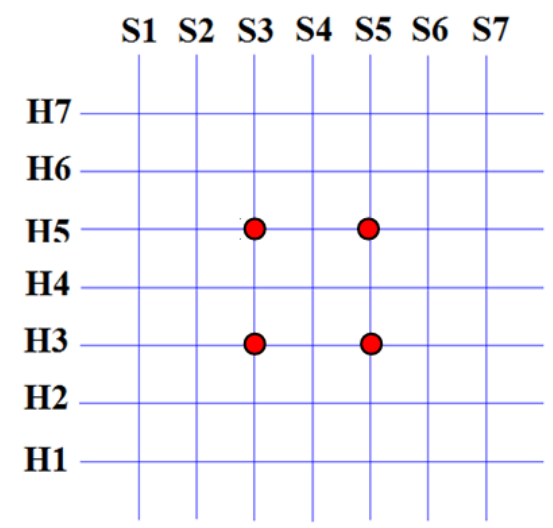

Figure 5. The position of the loading point of the cable net structures

The maximum nodal displacement of cable net was found to be at the central node of cable net and was measured using linear variable displacement transducer (LVDT). The glass stiffness contribution is based on the displacement of cable net with and without glass panes. Equation 1 is used to determine GSC in percentage.
$\mathrm{GSC}=\left[\left(\mathrm{D}_{0}-\mathrm{D}_{1}\right) / \mathrm{D}_{0}\right] \times 100$ where, $\mathrm{D}_{0}$ is nodal displacement of cable net without glass pane and $\mathrm{D}_{1}$ is nodal displacement of cable net with glass pane. $D_{0}$ and $D_{1}$ was measured at the same node of cable net without and with glass pane, respectively.

\section{RESULTS AND DISCUSSION}


Table 2. The maximum nodal deflection of CCN, FCN, CCN and CCNG at the maximum applied load.

\begin{tabular}{|c|c|c|}
\hline Cable net systems & $\begin{array}{c}\text { Deflection } \\
(\mathrm{mm})\end{array}$ & $\begin{array}{c}\text { Glass stiffness } \\
\text { contribution } \\
(\%)\end{array}$ \\
\hline FCN & 24.28 & 18.0 \\
\hline FCNG & 19.90 & 18.1 \\
\hline CCN & 21.51 & \multirow{2}{*}{18.0} \\
\hline CCNG & 17.61 & \\
\hline
\end{tabular}

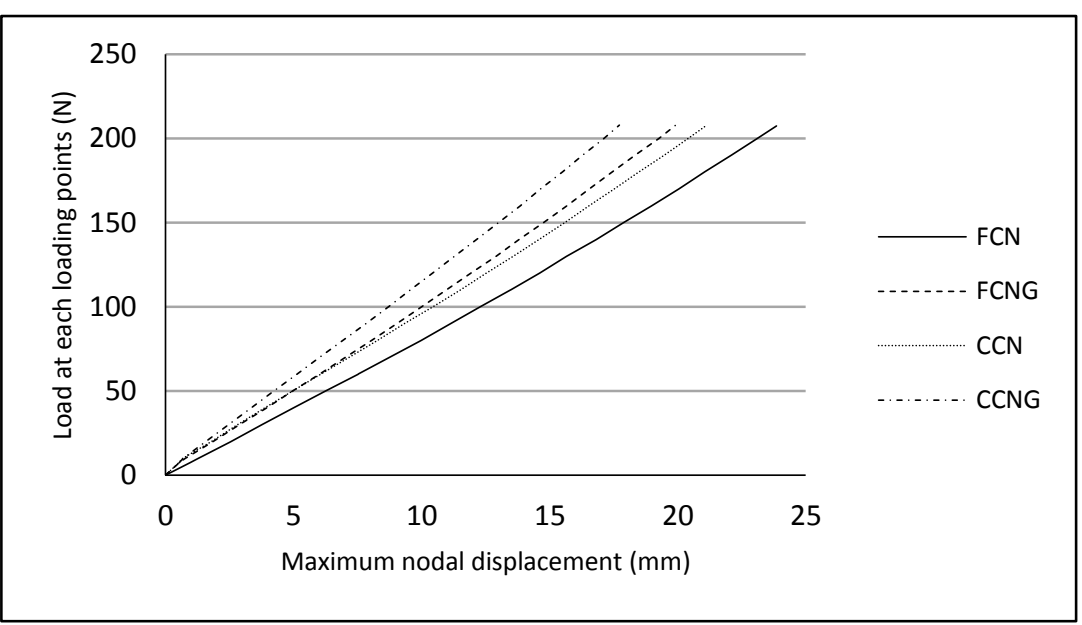

Figure 6. Maximum nodal deflection of flat and curved cable nets with and without glass panes

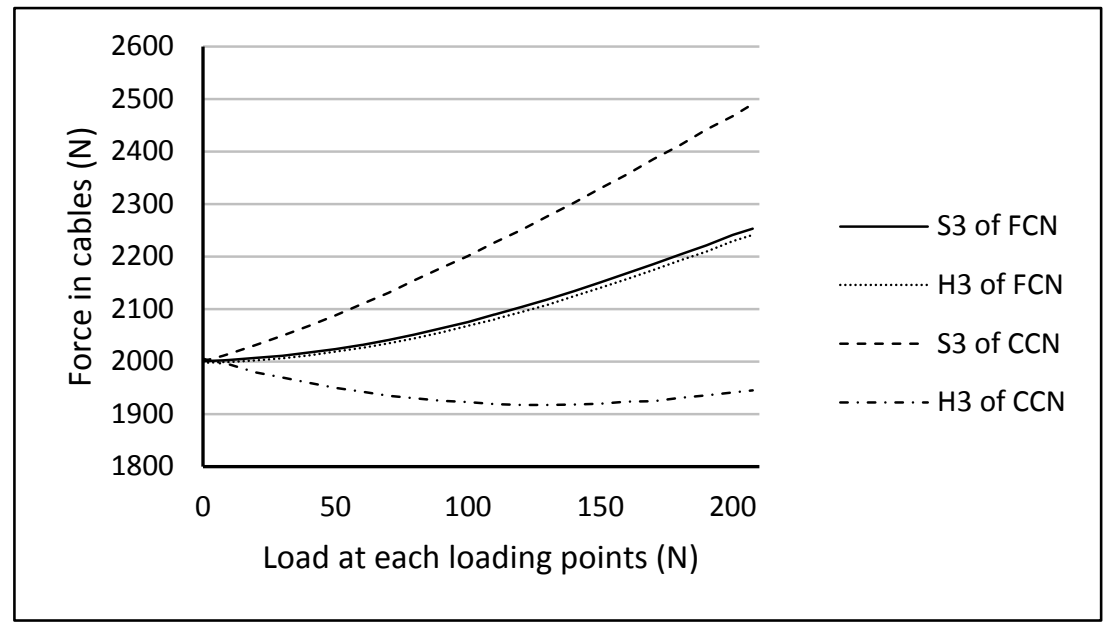

Figure 7. Maximum nodal deflection of flat and curved cable nets with and without glass panes

Figure 6 shows the maximum nodal displacement of flat and doubly-curved cable nets with and without glass panes. The maximum nodal deflection of FCN and CCN cable nets are $24.28 \mathrm{~mm}$ and $21.51 \mathrm{~mm}$, respectively. In addition, the maximum nodal displacement of FCNG and CCNG were $19.9 \mathrm{~mm}$ and 17.61 , respectively. The percentage difference of FCN-CCN and FCNG-CCNG are approximately the same at $11.5 \%$ when the maximum load was applied. Although the glass was fitted on the cable net structure, it does not show any additional increment in the stiffness contribution. The stiffness of $\mathrm{CCN}$ is higher than the FCN as the load was increased. This is because the increment of force in the cable in $\mathrm{CCN}$ is greater than that of the cable in FCN as shown in Figure 7. Although the force in cable $\mathrm{H} 3$ in $\mathrm{CCN}$ decreased, the increment of force in cable S3 in
$\mathrm{CCN}$ is rather high. The force in cable $\mathrm{H} 3$ in $\mathrm{CCN}$ reduced to a certain load stage before it increased as the load was increased. This was because the shape of cable $\mathrm{H} 3$ that was initially in hogging shape changed to nearly flat shape. Cables S1-S7 in CCN were the load bearing cable while cables $\mathrm{H} 1-\mathrm{H} 7$ in $\mathrm{CCN}$ were the supporting cable. In addition, the force in cable S3 increased around $25 \%$ of the initial pre-stress force when the maximum load was applied. The force in cable $\mathrm{H} 3$ in $\mathrm{CCN}$ reduced only by $4.1 \%$ of the initial pre-stress force as compared to increment of force in cable S3 in CCN. In addition, the force in cables $\mathrm{S} 3$ and $\mathrm{H} 3$ in $\mathrm{FCN}$ increased by approximately $12 \%$ of the initial pre-stress force which was about half of the increment of force in cable S3 in $\mathrm{CCN}$. These have proved that the curvature has an important role in increasing the stiffness of the cable net 
structure. It can be seen that the deflection of cable net is reduced when a certain level of curvature introduced to the initial configuration of cable net. Although the level of curvature of the doubly-curve cable net considered in this study was shallow and nearly flat, it shown significant effect on the stiffness of the cable net.

Typically the stiffness of cable net is mostly influenced by the force in the cable. However, with the additional of glass in the structural system, it contributes to the stiffness of the whole structure. The maximum nodal deflection of CCN, FCN, FCNG and CCNG at the maximum load applied are summarized in Table 2. It shows that the glass has significant contribution on the stiffness of the cable net structure. The GSC of both net increased when the load was increased but it is consistent at the maximum load applied. It shows that the glass panes only contributes to the stiffness at the beginning of the loading stage and consistent as the cable stiffened. By considering the contribution of glass in the design of cable net structure, the design force in the cable could be possible smaller and allow smaller size of cable to be used or the size of supporting structure for the cable net could be achieved.

\section{CONCLUSIONS}

The main conclusion are:

1. The introduction of certain level of curvature to the flat cable net could significantly improve its structural

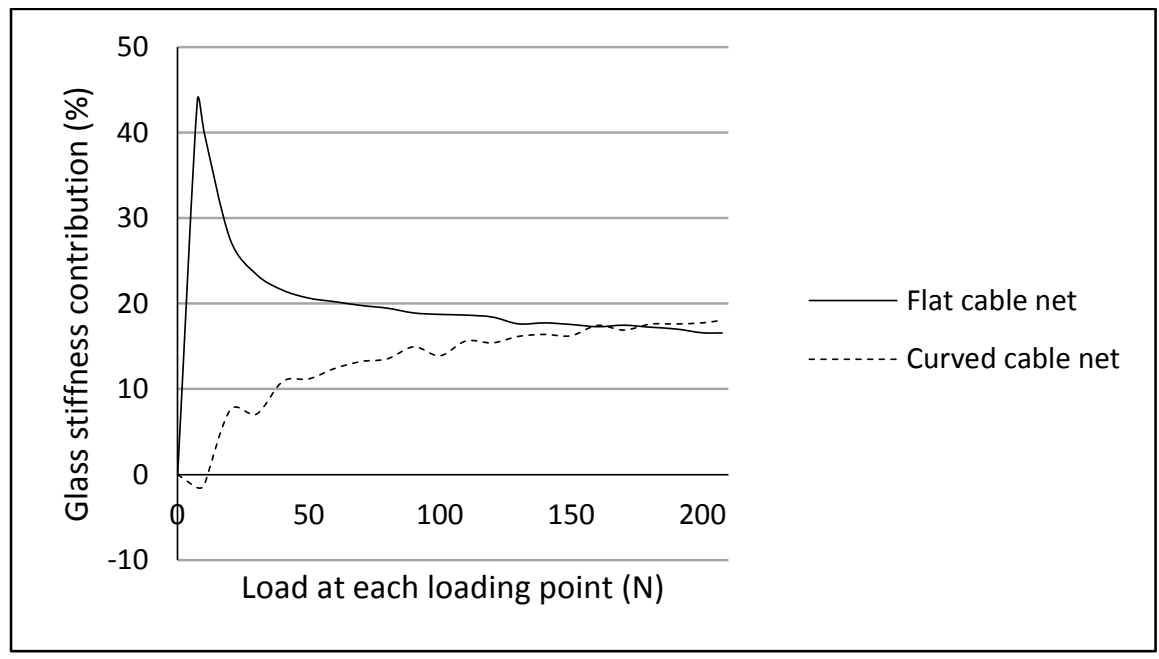

Figure 8. Contribution of glass on the stiffness of the cable net façade systems

cable net configurations is approximately $18 \%$ at the maximum load applied.

The increment of the maximum nodal deflection of cable net with glass and the load applied seems to be linear. This characteristic could be used to predict the approximate maximum nodal displacement under design loading on cable net structure without concerning the effect of geometric nonlinearity of cable. In addition, the maximum nodal deflection of FCNG is $7.5 \%$ lower than that of $\mathrm{CCN}$. This has shown that the performance of FCNG is better than CCN. The percentage different of the deflection between cable net structure with and without glass indicates that smaller size of cable could be used to meet the same deflection criterion of cable net. The maximum nodal deflection of cable net is one of the parameters that are used to check against the deflection criterion of the cable net systems. Besides the geometry of cable net structure, the glass panes also has shown significant contribution towards the stiffness of the structure.

Figure 8 shows the contribution of the glass panes on the stiffness of both flat and curved cable net façade systems. Glass stiffness contribution (GSC) of flat cable net was approximately $40 \%$ at the initial loading stage but it decreased to $18 \%$ at the maximum load applied. This was due to increment of force in the cable as the load was increased. However, the GSC of curved cable stiffness. The doubly-curve cable net considered in this study was geometrically to be nearly flat but it could improve the structural stiffness of the cable net. The deflection of doubly-curved cable net is approximately up to $11.5 \%$ smaller than that of flat cable net when subjected to maximum load considered in this study.

2. Another factor that influenced the stiffness of the structure is the glass panes. From this study, it has been proven that the glass has increased the stiffness of the cable net structure by approximately $18 \%$.

3. The contribution of glass panes on the stiffness of flat cable net is high at the beginning of load and it reduced as the load was increased. Meanwhile, the GSC of curved cable net increased as the load was increased. However, GSC of both configurations remained steady at the maximum load applied.

\section{V.ACKNOWLEDGEMENTS}

This work was funded by the Department of Civil and Environmental Engineering, Faculty of Engineering and Physical Sciences, University of Surrey. The authors would like to thank the laboratory technician Mr. Peter Haynes and Mr. Nigel Mobbs for the technical contributions.

\section{VI.REFERENCES}

[1] H. Nam and N.T. Nghia, "Estimation of cable tension using measured natural frequencies". Procedia Engineering, Vol. 14, pp. 1510-1517, 2011. 
The Third International Conference on Civil Engineering Research (ICCER)

August $1^{\text {st }}-2^{\text {nd }}$ 2017, Surabaya - Indonesia

[2] Q. Wang, P. Jiang and X. Kong, "The effects of structural parameter variation on cable force of fast cable-Net structure". Advances in Mechanical Engineering, 6, 912158, 2014.

[3] R.-Q. Feng, Y. Wu and S.-Z. Shen, "Working mechanism of single-layer cable-net supported glass curtain walls", Advances in Structural Engineering, 10(2), 183-195, 2007.

[4] R.-Q Feng, L.-L Zhang, Y. Wu and S.-Z. Shen, "Dynamic performance of cable-net façade", Journal of Constructional Steel Research, 65, 2217-2227, 2009.

[5] G. Shi, Y. Zuo, X. Shi, Y. Wang, and Z. Guo, "Influence of damages on static behaviour of single-layer cable-net supported glass curtain wall: Full-scale model test", Front. Archit. Civ. Eng. China, 4(3), 383-395, 2010. 